Address for Correspondence: Prof. Patrick M Honore, MD, PhD, Professor of Medicine, ICU Department, Centre Hospitalier Universitaire Brugmann, 4, Place Van Gehuchten 1020, Brussels, Belgium

E-mail: Patrick.Honore@CHU-

Brugmann.be

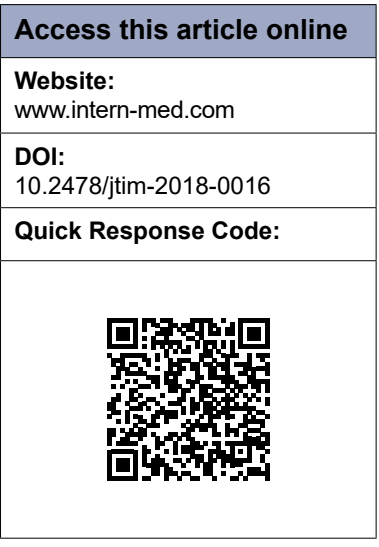

\title{
What a clinician should know about a renal replacement membrane?
}

\author{
Patrick M. Honore ${ }^{1}$, Herbert D. Spapen ${ }^{2}$ \\ 'ICU Department, Centre Hospitalier Universitaire Brugmann, Brussels, Belgium; \\ 'Universitair Ziekenhuis Brussel, VUB University, Brussels, Belgium
}

\section{WHAT IS A RENAL REPLACEMENT THERAPY MEMBRANE?}

A renal replacement therapy (RRT) membrane is a semi-permeable filter with pores of approximately 35,000 Da. A logarithmic linear relationship exists between molecular weight (MW) cut-off and membrane pore size. A $1 \mathrm{kDa} \mathrm{MW}$ cut-off corresponds to about $1.3 \mathrm{~nm}$ in membrane pore size, whereas a $10 \mathrm{kDa}$ membrane has a pore size of about $2.9 \mathrm{~nm}$. Along this membrane, the diffusion and convection processes can take place. Diffusion follows a concentration gradient [as in intermittent hemodialysis (IHD)] and is the ideal method to remove small $(<500 \mathrm{Da})$ molecules such as creatinine. Convection follows a hydrostatic pressure gradient [as in continuous veno-venous hemofiltration $(\mathrm{CVVH})]$ and is the best method to remove middle-large (between $500 \mathrm{Da}$ and $60 \mathrm{kDa}$, such as the 13,750 Da beta- 2 microglobulin) and large molecules (between 60 to $100 \mathrm{kDa}$, such as the $70 \mathrm{kDa}$ albumin). The theoretical cut-off is $35 \mathrm{kDa}$ (so only low-middle molecules will pass the membrane when using convection). When diffusion and convection are used simultaneously in continuous mode, this is called continuous veno-venous hemodiafiltration (CVVHDF). ${ }^{[1]}$

\section{WHAT IS A BIOCOMPATIBLE MEMBRANE?}

Biocompatibility refers to any harmful effect induced by the contact of blood with the dialysis membrane. The formerly used cuprophane membranes caused major blood interface interactions inducing unwarranted side-effects. Today, biocompatible polysulphone, polyethersulphone or polyacrylonitrile (PAN) (e.g., Acrylonitrile (AN) 69) membranes are used. ${ }^{[2]}$

\section{WHICH MEMBRANE SHOULD I CHOOSE FOR THE AVERAGE INTENSIVE CARE UNIT PATIENT?}

A simple polysulphone hemofilter is suitable in a vast majority of patients. This membrane is robust, cheap, and resistant to contamination (less hydraulic membrane permeability loss). In contrast with the highadsorbent PAN membranes, polysulphone membranes also do not adsorb antibiotics, which facilitates antibiotic adaptation during continuous RRT (CRRT). ${ }^{[3]}$

\section{WHAT IS THE NORMAL POROSITY OF A MEMBRANE?}

A classic membrane has a cut-off of 30-35 $\mathrm{kDa}$. Membranes used for convection (CVVH) have similar porosity whereas the cut-off value is lower (approximately $5 \mathrm{kDa}$ ) in diffusion mode (IHD). ${ }^{[9]}$

In clinical practice, high $(60 \mathrm{kDa})$ or median (50 kDa) cut-off membranes are almost never used. Higher cut-off membranes may increase the risk of albumin loss. ${ }^{[4]}$

\section{WHAT MEMBRANE SURFACE SHOULD BE USED?}

When using unfractionated heparin (UFH) and higher blood flows, surfaces of 1.5 
to $2 \mathrm{~m}^{2}$ are needed. Membrane surface can be decreased when regional citrate anticoagulation (RCA) is used. A 1 $\mathrm{m}^{2}$ surface is ideal, reducing blood-membrane interactions and shear stress. ${ }^{[5]}$

\section{SHOULD I PRE-COAT OR SOAK THE MEMBRANE BEFORE USE?}

Filter life of most membranes (even under RCA) is improved after soaking them with 5,000 IU/L UFH. Contra-indications for UFH use should always be considered. ${ }^{[6]}$

\section{HOW FREQUENTLY SHOULD I CHANGE THE MEMBRANE?}

In the UFH era, it was recommended to change the membrane every 24 to $48 \mathrm{~h}$ guided by filter pressure drop and transmembrane pressure (TMP) increase. RCA, however, enables to maintain filter porosity up to 72 or $96 \mathrm{~h}^{\left[{ }^{[7]}\right.}$

\section{WHAT IS MEANT BY MEMBRANE CLOTTING?}

Membrane clotting means that thrombosis occurs at the intra-arterial side of the membrane. This occurs relatively early during continuous RRT.

For example: Access pressure $-70 \mathrm{mmHg}$ (-50 to -150 $\mathrm{mmHg}$ ); Return pressure $90 \mathrm{mmHg}$ (50 to $150 \mathrm{mmHg}$ ); Filter pressure $350 \mathrm{mmHg}(100$ to $250 \mathrm{mmHg})=$ indicative of filter clotting.

This can be monitored over time by assessing the pressure drop (P-Drop), which is the pressure reduction that occurs as blood flow passes the filter (P-Drop $=$ Filter pressure - Return pressure).

For example: Baseline Filter pressure is $100 \mathrm{~mm} \mathrm{Hg}$ and Return pressure $90 \mathrm{~mm} \mathrm{Hg}$. Thus, P-Drop is $10 \mathrm{~mm} \mathrm{Hg}$ and low. After $24 \mathrm{~h}$, Filter pressure has increased to 200 $\mathrm{mm} \mathrm{Hg}$ and Return pressure is $110 \mathrm{~mm} \mathrm{Hg}$. Now, P-Drop is $90 \mathrm{mmHg}$ which suggests membrane clotting. ${ }^{[8]}$

\section{HOW CAN I DETECT AND PREVENT MEMBRANE CLOTTING?}

Membrane clotting is detected by closely monitoring P-Drop and Filter pressure. When early $(<6 \mathrm{~h})$ filter clotting occurs, the venous access must be checked and eventually flushed with normal saline. In case of UFH use, clotting can be prevented by increasing the filtration fraction (increasing blood flow without increasing ultrafiltration $[\mathrm{UF}]$ rate or vice versa). ${ }^{[8]}$

\section{WHAT IS MEANT BY MEMBRANE CLOGGING?}

Membrane clogging occurs later than clotting and is characterized by the formation of a protein "cake". Protein progressively obturates the membrane pores from the blood side. Accordingly, the TMP needed to suck out water and molecules will increase to a point that the membrane function becomes ineffective. A persistent and gradual rise in TMP usually indicates filter clogging. This is usually accompanied by a gradual filter pressure rise and effluent pressure drop. Observing this trend together with a TMP exceeding $+300 \mathrm{mmHg}$, requires filter replacement. TMP represents the pressure exerted on the filter membrane during operation $(\mathrm{TMP}=$ Filter pressure + Return pressure $/ 2$ - Effluent pressure) and is recorded automatically. ${ }^{[0]}$

\section{HOW CAN I DETECT AND PREVENT MEMBRANE CLOGGING?}

Membrane clogging is detected by the close monitoring of TMP and UF pressure. It can be avoided by decreasing the UF rate and thus TMP or by using RCA instead of UFH for anticoagulation. ${ }^{[9]}$

\section{WHAT IS MEANT BY FILTRATION FRACTION?}

The filtration fraction (FF) represents the percentage of plasma that is removed as UF and then replaced by substitution fluid. Under UFH anticoagulation, filtration fraction (FF) should remain between 16 and $20 \%$ to avoid filter clotting. RCA allows FF levels up to $30-33 \%$. As such, blood flow needed to obtain adequate UF can be reduced and a vascular access allowing $150 \mathrm{~mL} / \mathrm{min}$ will be sufficient. UFH anticoagulation, depending on the patient's body weight, requires 250 to $350 \mathrm{~mL} / \mathrm{min}$ to keep the $\mathrm{FF}$ below $20 \%$. In other words, the FF is the fraction of plasma water removed from the blood during UF. It should be kept in the range of $16-20 \%$ to avoid equalization of oncotic pressure to TMP and filtration/pressure equilibrium. This can be expressed as: (Post-Dilution + Pre-Dilution + Filter Loss) / (Blood Flow + Pre-Dilution). Ideally, the formula should also include the hematocrit in the Hemofilter but the latter is not regularly controlled. ${ }^{[10]}$

\section{WHAT FF IS PREFERRED WHEN USING UNFRACTIONATED HEPARIN?}

FF should be kept between 16 and 20\%.Variations of FF will depend on the ratio between blood flow and UF rate. To keep FF low, a blood flow up to $350-400 \mathrm{~mL} / \mathrm{min}$ might be needed in obese patients. ${ }^{[10]}$ 
WHAT FF IS PREFERRED WHEN USING REGIONAL CITRATE ANTICOAGULATION?

RCA allows an FF up to 30-33\%. Therefore, the same UF rate is obtained at lower blood flow. ${ }^{[1]}$

\section{WHAT IS THE SIEVING COEFFICIENT?}

The Sieving Coefficient (SC) is the ratio of UF to plasma solute concentration.

$\mathrm{SC}=1$ reflects complete permeability (for urea and creatinine);

$\mathrm{SC}=0$ reflects complete impermeability;

SC $>1$ requires an external energy source.

During UF, the driving pressure forces solutes (such as urea and creatinine) against the membrane. The extent of solute penetration through the pores of the membrane is determined by the membrane SC for that molecule.

Major factors determining the SC are solute molecular size, protein binding, volume of distribution and filter porosity. ${ }^{[12]}$

\section{WHAT SHOULD BE THE TMP IN ADULT RRT?}

A TMP between 50 and $250 \mathrm{~mm} \mathrm{Hg}$ is acceptable for adult CRRT. When TMP exceeds $300 \mathrm{mmHg}$, the membrane must be changed. ${ }^{[13]}$

\section{WHAT SHOULD BE THE TMP IN PEDIATRIC OR NEONATAL RRT?}

In the pediatric and neonatal setting, a membrane change must be performed when TMP exceeds $450 \mathrm{mmHg}$. This is due to the fact that the membrane has a much smaller surface and thus needs and tolerates a higher TMP. ${ }^{[13]}$

\section{WHAT IS MEANT BY THE HAEMOPERMEABILITY INDEX?}

The Hemopermeability Index (HPI) is the spontaneous UF rate divided by the TMP and reflects the functional capacity of the membrane. A decrease of spontaneous UF rate for the same TMP suggests membrane clogging. HPI is mostly used during spontaneous UF during cardiac surgery. ${ }^{[14]}$

\section{HOW MUST THE NEW ADSORPTIVE MEMBRANES BE JUDGED?}

The clinical superiority of the novel adsorptive AN69 oXiris, AN-69-surface treated (ST) or Poly(methyl methacrylate) (PMMA) membrane has not been established. Of note is that hydrophilic antibiotics are largely adsorbed by these membranes, necessitating significant dose adjustments. ${ }^{[15]}$

\section{WHICH DRUGS ARE REMOVED BY CRRT?}

Un(protein)bound and low $(<500 \mathrm{Da})$ MW drugs are removed (e.g., salicylates, methanol, ethylene glycol, barbiturates, lithium, penicillin, carbapenems, aminoglycosides, cephalosporins, vancomycin, metformin, etc..$^{[16]}$

\section{WHICH DRUGS ARE NOT REMOVED BY CRRT?}

Protein-bound agents, high MW drugs, and drugs with a high volume of distribution are not removed (e.g., digoxin, tricyclic antidepressants, phenytoin, benzodiazepines, betablockers (except atenolol), etc.). ${ }^{[16]}$

\section{WHAT ARE HIGH-FLUX MEMBRANES?}

High-flux membranes have a larger pore size and thus increase the clearance by allowing larger molecules to pass through the membrane (at least in theory) as well as more UF flow for the same TMP. Almost all novel biocompatible CRRT membranes are of high-flux type. ${ }^{[17]}$

\section{Conflict of Interests}

The authors declare to have no competing interests

\section{REFERENCES}

1. Neri M, Villa G, Garzotto F, Bagshaw S, Bellomo R, Cerda J, et al. Nomenclature for renal replacement therapy in acute kidney injury: basic principles. Crit Care 2016; 20: 318.

2. Oshihara W, Ueno Y, Fujieda H. A New Polysulfone Membrane Dialyzer, NV, with Low-Fouling and Antithrombotic Properties. Contrib Nephrol 2017; 189: 222-9.

3. Zhu L, Song H, Wang J, Xue L. Polysulfone hemodiafiltration membranes with enhanced anti-fouling and hemocompatibility modified by poly(vinyl pyrrolidone) via in situ cross-linked polymerization. Mater Sci Eng C Mater Biol Appl 2017; 74: 159-66.

4. D'souza MA, Ravn A, Jorns C, Nowak G, Isaksson B. Membrane cut-off does not influence results regarding the measurement of small molecules - a comparative study between 20 - and $100-\mathrm{kDa}$ catheters in hepatic 
microdialysis. Clin Physiol Funct Imaging 2014; 34: 109-13.

5. Ronco C, Neri M, Lorenzin A, Garzotto F, Clark WR. Multidimensional Classification of Dialysis Membranes. Contrib Nephrol 2017; 191: 115-26.

6. Lindsay RM, Rourke JT, Reid BD, Linton AL, Gilchrist T, Courtney J, et $a l$. The role of heparin on platelet retention by acrylonitrile co-polymer dialysis membranes. J Lab Clin Med 1977; 89: 724-34.

7. Honore PM, Jacobs R, Joannes-Boyau O, De Regt J, Boer W, De Waele E, et al. Septic AKI in ICU patients. diagnosis, pathophysiology, and treatment type, dosing, and timing: a comprehensive review of recent and future developments. Ann Intensive Care 2011; 1: 32.

8. Cerdá J, Baldwin I, Honore PM, Villa G, Kellum JA, Ronco C, et al. Role of Technology for the Management of AKI in Critically Ill Patients: From Adoptive Technology to Precision Continuous Renal Replacement Therapy. Blood Purif 2016; 42: 248-65.

9. Joannidis M, Oudemans-van Straaten HM. Clinical review: Patency of the circuit in continuous renal replacement therapy. Crit Care 2007; 11: 218.

10. Villa G, Neri M, Bellomo R, Cerda J, De Gaudio AR, De Rosa S, et al. Nomenclature for renal replacement therapy and blood purification techniques in critically ill patients: practical applications. Crit Care 2016; 20: 283.

11. Jacobs R, Honoré PM, Bagshaw SM, Diltoer M, Spapen HD. Citrate Formulation Determines Filter Lifespan during Continuous VenoVenous Hemofiltration: A Prospective Cohort Study. Blood Purif 2015; 40: 194-202.
12. Matson J, Zydney A, Honoré PM. Blood filtration: new opportunities and the implications of systems biology. Crit Care Resusc 2004; 6: 209-17.

13. Honoré PM, Matson JR. Hemofiltration, adsorption, sieving and the challenge of sepsis therapy design. Crit Care 2002; 6: 394-6.

14. Cerdá J, Villa G, Neri M, Ronco C. Technology in Medicine: Moving Towards Precision Management of Acute Kidney Injury. Contrib Nephrol 2018; 193: 89-99.

15. Honore PM, Jacobs R, Joannes-Boyau O, De Regt J, De Waele E, van Gorp V, et al. Newly designed CRRT membranes for sepsis and SIRS--a pragmatic approach for bedside intensivists summarizing the more recent advances: a systematic structured review. ASAIO J 2013; 59: 99-106.

16. Honore PM, Jacobs R, De Waele E, Spapen HD. Applying pharmacokinetic/pharmacodynamic principles for optimizing antimicrobial therapy during continuous renal replacement therapy. Anaesthesiol Intensive Ther 2017; 49: 412-8.

17. Donadio C, Tognotti D, Caponi L, Paolicchi A. $\beta$-trace protein is highly removed during haemodialysis with high-flux and super high-flux membranes. BMC Nephrol 2017; 18: 68.

How to cite this article: Honore PM, Spapen HD. What a clinician should know about a renal replacement membrane?. J Transl Intern Med 2018; 6: 62-5. 